CARDIOVASCULAR MEDICINE

\title{
Atherosclerosis-like lesions of the aortic valve are common in adults of all ages: a necropsy study
}

\author{
J Kuusisto, K Räsänen, T Särkioja, E Alarakkola, V-M Kosma
}

Heart 2005;91:576-582. doi: 10.1136/hrt.2004.036848

See end of article for authors' affiliations

.....................

Correspondence to:

Dr Johanna Kuusisto,

Cardiology Unit,

Department of Medicine,

Kuopio University Hospital,

PO Box 1777, FIN-70211

Kuopio, Finland;

johanna.kuusisto@kuh.fi

Accepted 7 June 2004

\begin{abstract}
Objective: To determine the presence and size of atherosclerosis-like lesions in aortic valves of unselected adults of all ages.

Design: Necropsy study.

Setting: Departments of Forensic Medicine and Pathology at the University of Oulu and the Oulu University Hospital in Finland.

Subjects: 48 consecutive unselected adult subjects ( 15 subjects aged 20-40 years, 17 aged 41-60, and 16 aged $\geqslant 61$ ) undergoing necropsy.

Main outcome measures: Detection of the presence of atherosclerosis-like lesions and mineralisation in aortic valves, and morphometrical measurement of the size of lesions.

Results: None of the necropsy subjects had aortic stenosis and only two subjects had macroscopic calcification of the aortic valve. Of 48 subjects, however, 45 had an atherosclerosis-like subendothelial thickening above the elastic lamina on the aortic side of at least one of the valve leaflets. Of 15 young subjects aged 20-40 years, eight had a lesion in the right coronary cusp of the aortic valve and 12 had a lesion in at least one of the three aortic valve leaflets. Of 17 middle aged subjects, 16 had an early lesion in the right coronary cusp and all had a lesion in at least one of the valve leaflets. In the oldest age group, all 16 subjects had a lesion in every valve leaflet. The mean lesion area in the three valve leaflets varied from $0.1-0.2 \mathrm{~mm}^{2}$ in young subjects, $0.5-0.8 \mathrm{~mm}^{2}$ in middle aged, and $1.3-2.3 \mathrm{~mm}^{2}$ in elderly subjects $(p<0.001)$. Microscopic calcification in the right coronary cusp of the aortic valve was observed in 12 of 17 middle aged and 14 of 16 elderly subjects but only in one young subject.

Conclusions: Atherosclerosis-like lesions in the aortic valve are prevalent in adults of all age groups, including young subjects aged $20-40$ years, suggesting that the disease process leading to aortic stenosis is common, often beginning in early adulthood.
\end{abstract}

A ortic stenosis is the most important valvar disease in aging Western populations. Clinical aortic stenosis is present in about $2 \%$ of subjects aged over 65 years. Aortic valve sclerosis, characterised by calcification and thickening of the aortic valve without ventricular outflow obstruction, is echocardiographically detectable in $26 \%$ of subjects in the same age group. ${ }^{1}$

Recent studies have shown that aortic stenosis shares several similarities with atherosclerosis. Firstly, in both diseases, lipids, inflammatory cells (mainly macrophages and T lymphocytes), protein, cholesterol crystals, and calcium deposits accumulate under the endothelium and above the elastic lamina, which is subsequently dislocated, disrupted, or duplicated. ${ }^{2-4}$ Apolipoproteins B, E, and (a), Chlamydia pneumoniae, and angiotensin converting enzyme have been found not only in coronary atheromas but also in stenosed aortic valves..$^{5-8}$ Secondly, cardiovascular risk factors are associated with aortic stenosis. ${ }^{1}{ }^{10}$ Thirdly, aortic valve sclerosis has been shown to predict cardiovascular mortality and morbidity independently of conventional risk factors, suggesting that aortic valve sclerosis may be a marker of silent coronary disease. ${ }^{11}{ }^{12}$ Thus, valvar aortic stenosis is probably caused by the same atherosclerotic disease process as coronary disease. ${ }^{92-15}$

Atherosclerosis-like lesions are found not only in stenosed aortic valves but also in non-stenosed valves of elderly subjects. ${ }^{2}$ In the study by Otto and colleagues, ${ }^{2}$ histological atherosclerosis-like changes were observed in macroscopically non-calcified aortic valves of elderly subjects. These changes were characterised by subendothelial thickening on the aortic side of the valve leaflet above the elastic lamina, the presence of lipids and fine mineralisation in and adjacent to these lesions, and macrophages as well as occasional $\mathrm{T}$ cells. These atherosclerosis-like lesions were interpreted to be the early lesion of aortic stenosis. ${ }^{2}$ It is not known, however, whether atherosclerosis-like changes are present in aortic valves of young and middle aged adults without aortic stenosis. Therefore, the present study aimed at determining the presence, size, and microscopic features of the atherosclerosis-like lesions in aortic valves of 48 unselected Finnish necropsy subjects aged $\geqslant 20$ years.

\section{METHODS}

\section{Subjects}

Aortic valves were obtained from 48 unselected consecutive subjects ( 15 subjects aged 20-40 years, 17 subjects aged 4160 years, and 16 subjects aged $\geqslant 61$ years) undergoing necropsy at the Departments of Forensic Medicine and Pathology at the University of Oulu and the Oulu University Hospital, northern Finland. The study groups were prospectively planned to include similar numbers of young, middle aged, and elderly adults. The cause of death was obtained from death certificates (table 1). Information about previous diseases and cardiovascular risk factors was obtained from death certificates and medical records, if available. None of the study subjects had a history of clinical aortic stenosis, endocarditis, or rheumatic valvar disease.

The study protocol was approved by the Finnish National Board of Medicolegal Affairs.

\section{Valve examination and preparation}

The ascending aorta was incised longitudinally during necropsy and the aortic valve was examined macroscopically 


\begin{tabular}{|c|c|c|c|}
\hline $\begin{array}{l}\text { Cadaver } \\
\text { number }\end{array}$ & Sex & $\begin{array}{l}\text { Age } \\
\text { (years) }\end{array}$ & Cause of death \\
\hline 1 & $\mathrm{~F}$ & 22 & Accident \\
\hline 2 & M & 23 & Suicide \\
\hline 3 & $M$ & 25 & Accident \\
\hline 4 & M & 35 & Suicide \\
\hline 5 & $\mathrm{~F}$ & 74 & Thyroid carcinoma \\
\hline 6 & M & 45 & Alcoholism \\
\hline 7 & M & 32 & Suicide \\
\hline 8 & M & 40 & Accident \\
\hline 9 & M & 25 & Accident \\
\hline 10 & $M$ & 66 & Ventricular carcinoma \\
\hline 11 & $\mathrm{~F}$ & 76 & Myocardial infarction \\
\hline 12 & M & 69 & Pancreatitis \\
\hline 13 & $M$ & 54 & Accident \\
\hline 14 & $\mathrm{~F}$ & 23 & Suicide \\
\hline 15 & M & 46 & Subarachnoidal bleeding \\
\hline 16 & $M$ & 22 & Accident \\
\hline 17 & $\mathrm{~F}$ & 28 & Homicide \\
\hline 18 & $M$ & 35 & Accident \\
\hline 19 & M & 66 & Lymphoma \\
\hline 20 & $\mathrm{~F}$ & 54 & Spinal atrophy \\
\hline 21 & M & 51 & Myocardial infarction \\
\hline 22 & M & 45 & Myocardial infarction \\
\hline 23 & M & 68 & Myocardial infarction \\
\hline 24 & $\mathrm{~F}$ & 51 & Breast cancer \\
\hline 25 & M & 53 & Myocardial infarction \\
\hline 26 & $\mathrm{~F}$ & 70 & Myocardial infarction \\
\hline 27 & $\mathrm{~F}$ & 72 & Myocardial infarction \\
\hline 28 & $\mathrm{~F}$ & 68 & Breast cancer \\
\hline 29 & M & 68 & Myocardial infarction \\
\hline 30 & M & 24 & Suicide \\
\hline 31 & M & 52 & Myocardial infarction \\
\hline 32 & M & 43 & Suicide \\
\hline 33 & $\mathrm{~F}$ & 52 & Pancreatitis \\
\hline 34 & M & 46 & Intestinal occlusion \\
\hline 35 & $\mathrm{~F}$ & 34 & Suicide \\
\hline 36 & $\mathrm{~F}$ & 39 & Suicide \\
\hline 37 & M & 30 & Homicide \\
\hline 38 & M & 49 & Accident \\
\hline 39 & M & 72 & COPD \\
\hline 40 & M & 53 & Myocardial infarction \\
\hline 41 & M & 46 & Myocardial infarction \\
\hline 42 & $\mathrm{~F}$ & 56 & Pneumonia \\
\hline 43 & M & 74 & Lymphoma \\
\hline 44 & M & 68 & Myocardial infarction \\
\hline 45 & $\mathrm{~F}$ & 75 & Tuberculosis \\
\hline 46 & M & 51 & Carcinoid tumour \\
\hline 47 & $M$ & 83 & Myocardial infarction \\
\hline 48 & $\mathrm{~F}$ & 71 & Breast cancer \\
\hline
\end{tabular}

by two pathologists (EA and TS). Fatty changes, calcification, and thickening of the valve were recorded, if present (table 1). Coronary arteries were excised and the presence and extent of macroscopic coronary artery disease were recorded.

Samples for histological and immunohistochemical analyses were taken vertically through each of the three leaflets of the aortic valve near the centre of the leaflet as described earlier. ${ }^{2}$ Leaflets were fixed in $10 \%$ formalin or methanol-Carnoy's solution and embedded in paraffin. All three leaflets were sampled to investigate the presence and size of atherosclerosis-like lesions. The right coronary cusp was sampled to study changes in elastic lamina, cellular changes including the presence of $\mathrm{T}$ lymphocytes and macrophages, and the presence of cholesterol crystals and calcification.

\section{Histological analysis}

Specimens were examined for the presence and location of the lesion, changes in the elastic lamina, and the presence of cholesterol crystals by Verhoeff-van Gieson staining, for leaflet thickening and cellularity by haematoxylin and eosin staining, and for the presence and location of calcification by von Kossa staining.

\section{Immunohistochemical analysis}

Commercially available monoclonal antibodies for macrophages (CD-68, DAKO) and T lymphocytes (CD-3, DAKO) were used to detect the presence of inflammatory cells.

\section{Evaluation of atherosclerosis-like lesions \\ Detection of lesions}

The presence of the atherosclerosis-like lesions in each aortic valve leaflet in all subjects was investigated at objective magnifications of 10-40× with a dual head Olympus BH-2 microscope or an image analyser (Quantimet 570, Leica, Cambridge, UK). A lesion was considered to be present if a subendothelial atherosclerosis-like lesion was observed above the elastic lamina of the aortic side of the aortic valve (fig 1 ). ${ }^{2}$ In the youngest age group, three of us (KR, JK, and V-MK) investigated all three aortic valve leaflets for the presence of atherosclerosis-like lesions. In the middle aged and elderly age groups, three of us (KR, JK, and V-MK) investigated the right coronary cusp of the aortic valve for the presence of atherosclerosis-like lesions and one of us (KR) investigated the left and non-coronary cusps, which two of us (JK and $\mathrm{V}$-MK) confirmed by randomly selected check ups. The lesion was considered to be present only if a unanimous opinion was reached.

\section{Measuring leaflet and lesion areas}

The total area of each of three aortic valve leaflets and the total area of the atherosclerosis-like lesion in each leaflet was measured with an image analyser (Quantimet 570) that two of us (KR and $\mathrm{JK}$ ) operated in an interactive mode. In the measurement of the lesion area, the subendothelial material over the elastic lamina on the aortic side of the valve leaflet was measured. ${ }^{2}$ Intraobserver variability of the lesion area (mean (SD)) in three subjects was $0.01(0.01) \mathrm{mm}^{2}$ for lesions in the right coronary cusp, $0.14(0.19) \mathrm{mm}^{2}$ for the lesions in the left coronary cusp, and $1.39(2.35) \mathrm{mm}^{2}$ for the lesions in the non-coronary cusp (non-coronary cusp measurements varied greatly due to inclusion or exclusion of a large calcium deposit loosely connected to the lesion area). Respective interobserver variabilities (KR and JK) in five subjects were $0.26(0.37), 0.12(0.11)$, and 0.10 (0.12) $\mathrm{mm}^{2}$.

\section{Histological evaluation}

Two of us (JK and V-MK) evaluated each set of histologically and immunohistochemically stained samples from the right coronary cusp at objective magnifications of $10-40 \times$ with a dual head Olympus BH-2 microscope. Each slide was examined systemically and each characteristic was evaluated on a predefined semiquantitative ( 0 to 4 ) scale, 0 indicating the normal amount (or absence) of the histological feature and 1 to 4 indicating an increasing pathological amount of the feature. Classification of lesions disagreed in fewer than $10 \%$ of the slides examined and consensus was reached on further review.

\section{Statistical analysis}

Data were analysed with the SPSS (SPSS Inc, Chicago, Illinois, USA) PC statistical software. The results of analyses of the continuous variables are given as mean (SEM). The three age groups were compared by the Mantel-Haenszel test for linear association for categorical data and by the nonparametric Kruskal-Wallis test for continuous variables over the three age groups. 

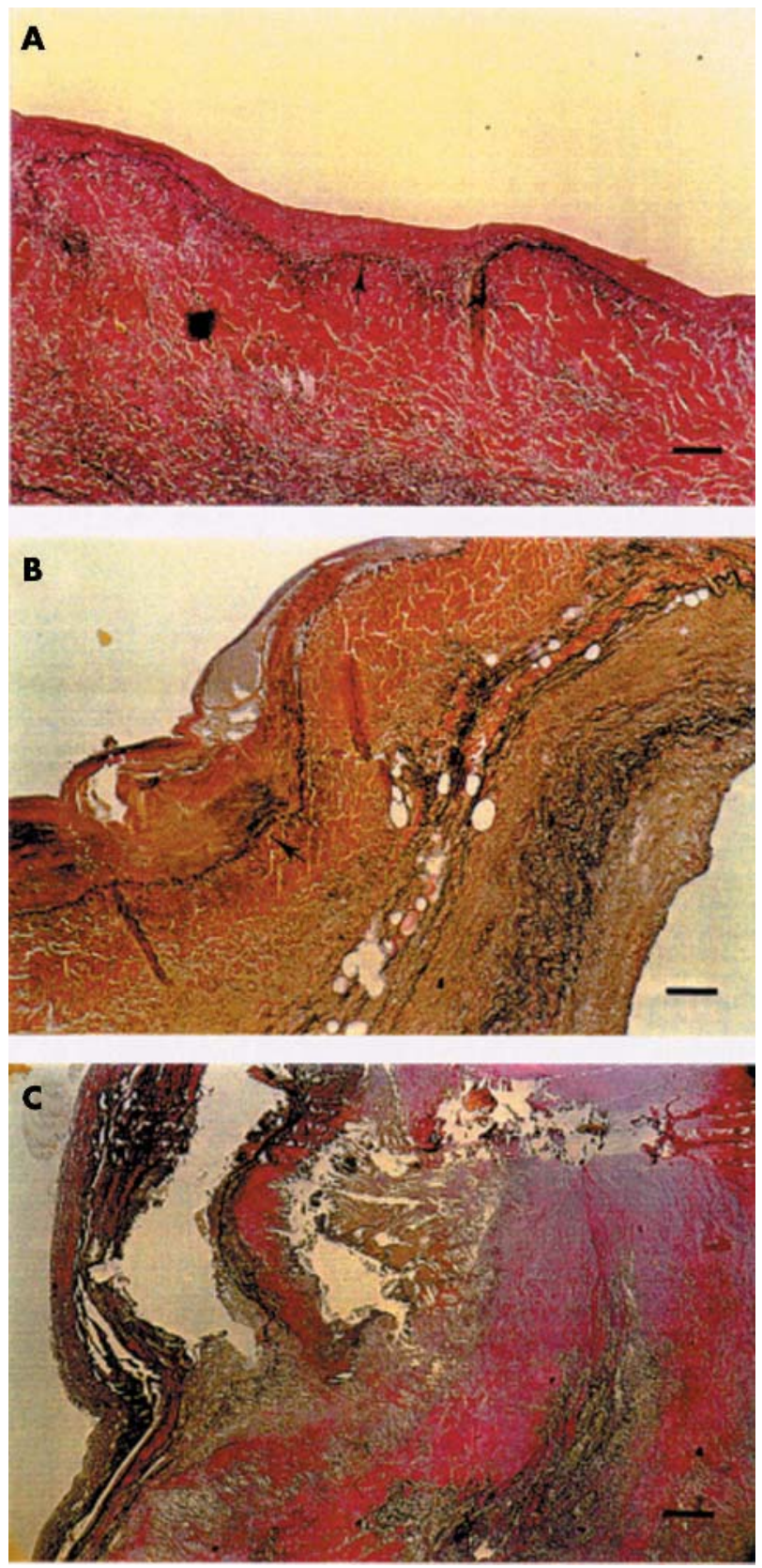

Figure 1 Photomicrographs of histological atherosclerosis-like lesions in aortic valves typically found in each of the age groups. (A) A small lesion in a young subject. Lesion is shown in the upper part of the photomicrograph above the elastic lamina (arrow). Bar $=100 \mu \mathrm{m}$. (B) A more advanced lesion in a middle aged subject (lesion above and to the left of the elastic lamina shown by an arrow). Bar $=100 \mu \mathrm{m}$. (C) An advanced lesion affecting the whole visible area of valvar leaflet in an elderly subject. Bar $=200 \mu \mathrm{m}$. Verhoeff-van Gieson stain.

\section{RESULTS}

\section{Clinical characteristics}

Table 2 shows clinical characteristics of the study subjects by age. There were 32 men and 16 women, with men predominating in all three age groups. The mean age of the three age groups was 29,50 , and 71 years. None of the young study subjects had a history of atherosclerotic vascular disease. A clinical history of cardiovascular risk factors was uncommon in the youngest age group, with only one young adult having a history of smoking. In contrast, two middle aged and nine elderly subjects had a history of coronary artery disease and two middle aged and three elderly subjects had a clinical history of other atherosclerotic vascular disease. Cardiovascular risk factors were also prevalent in both middle aged and elderly study subjects. Acute myocardial infarction was the cause of death of 13 patients (in six patients aged 4060 years and in seven patients aged $\geqslant 61$ years) (table 1 ). In all young subjects the cause of death was accident or suicide.

\section{Macroscopic findings in aortic valves and coronary arteries}

None of the study subjects had a macroscopically stenosed, bicuspid, or rheumatic aortic valve or signs of endocarditis. Macroscopic valvar calcification was detectable in only two subjects of the oldest age group (table 2).Three middle aged subjects and four elderly subjects had macroscopic fatty changes in their valves. All subjects of the youngest age group and 14 of 17 middle aged and nine of 16 elderly subjects had a macroscopically normal valve.

In the macroscopic examination of coronary arteries (table 2), 10 of 15 subjects in the youngest age group had fatty streaks or small atheromas in their coronary arteries. In the middle aged and oldest age groups, all subjects had fatty streaks, small or significant atheromas, or complicated plaques in their coronary arteries. Macroscopic signs of acute myocardial necrosis were found in two middle aged and two elderly subjects. In all age groups, atherosclerotic coronary lesions, when present, were found in two or three coronary arteries in most of the cases.

\section{Prevalence of atherosclerosis-like lesions in aortic valves}

Figure 2 shows the prevalence of atherosclerosis-like lesions in the aortic valve by age. Of 48 subjects, 45 had an atherosclerosis-like subendothelial thickening above the elastic lamina on the aortic side of at least one of the valve leaflets. Of 15 young subjects aged 20-40 years, eight had a lesion in the right coronary cusp of the aortic valve and 12 had a lesion in at least one of the three aortic valve leaflets. Of 17 middle aged subjects, 16 had an early lesion in the right coronary cusp and all had a lesion in at least one of the valve leaflets. In the oldest age group, all 16 subjects had a lesion in every valve leaflet.

\section{Size of atherosclerosis-like lesions in aortic valves}

Figure 1 shows typical aortic valve lesions in young, middle aged, and elderly adults. Table 3 shows the areas of each aortic valve leaflet and atherosclerosis-like lesions in each valve leaflet by age. In the youngest group, the mean area of the early lesion in the three aortic valve cusps varied from $0.1-0.2 \mathrm{~mm}^{2}$, in the middle aged group from $0.5-0.8 \mathrm{~mm}^{2}$, and in the oldest group from $1.3-2.3 \mathrm{~mm}^{2}(\mathrm{p}<0.001)$.

\section{Histological and immunohistochemical features of atherosclerosis-like lesions}

Table 4 shows the histological and immunohistochemical findings in the right coronary cusp of the aortic valve by age. In the youngest group, the lesion was usually located at the base or tip of the valve, but with increasing age the lesion was more diffuse, affecting all parts of the valve cusp. The changes in the elastic lamina were mild in the young subjects, moderate in the middle aged, and increasingly complicated in oldest subjects. Valvar cellularity was increased in six young, 14 middle aged, and 15 elderly subjects. Macrophages (immunohistochemical analysis of the right coronary cusp was available for 21 study subjects) were found in two valves of the young subjects, five valves of the middle aged subjects, and four valves of the elderly subjects. $\mathrm{T}$ lymphocytes (immunohistochemical analysis of the right coronary cusp available for 19 study subjects) in or adjacent 


\begin{tabular}{|c|c|c|c|c|}
\hline & \multicolumn{3}{|c|}{ Age group (years) } & \multirow[b]{2}{*}{ p Value ${ }^{*}$} \\
\hline & $\begin{array}{l}1(20-40) \\
(n=15)\end{array}$ & $\begin{array}{l}2(41-60) \\
(n=17)\end{array}$ & $\begin{array}{l}3(\geqslant 61) \\
(n=16)\end{array}$ & \\
\hline Men/women & $10 / 5$ & $13 / 4$ & $9 / 7$ & \\
\hline Age (years) & $29.1(1.6)$ & $49.8(0.90)$ & $71.3(1.1)$ & \\
\hline \multicolumn{5}{|l|}{ Clinical history } \\
\hline Coronary artery disease & 0 & 2 & 9 & $<0.001$ \\
\hline Other atherosclerotic disease & 0 & 2 & 3 & $<0.001$ \\
\hline Hypertension & 0 & 4 & 6 & $<0.001$ \\
\hline Diabetes & 0 & 1 & 4 & $<0.001$ \\
\hline Smoking & 1 & 1 & 4 & 0.031 \\
\hline Cholesterol > $>0.0 \mathrm{mmol} / \mathrm{l}$ & 0 & 6 & 4 & NS \\
\hline $\mathrm{HDL}$ cholesterol < $1 \mathrm{mmol} / \mathrm{l}$ & 0 & 3 & 3 & NS \\
\hline \multicolumn{5}{|l|}{ Necropsy findings (macroscopic) } \\
\hline \multicolumn{5}{|l|}{ Aortic valve } \\
\hline Normal & 15 & 14 & 9 & \\
\hline Fatty changes & 0 & 3 & 4 & \\
\hline Calcified & 0 & 0 & 2 & \\
\hline Leaky & 0 & 0 & 1 & 0.008 \\
\hline \multicolumn{5}{|l|}{ Coronary arteries } \\
\hline Normal & 5 & 0 & 0 & \\
\hline Fatty streaks & 8 & 3 & 3 & \\
\hline Small atheromas $(<50 \%)$ & 2 & 9 & 4 & \\
\hline Significant atheromas ( $\geqslant 50 \%$ ) & 0 & 1 & 1 & \\
\hline Complicated lesions & 0 & 4 & 8 & $<0.001$ \\
\hline Acute myocardial infarction & 0 & 2 & 2 & NS \\
\hline \multicolumn{5}{|c|}{ Number of affected coronary arteries } \\
\hline 0 & 5 & 0 & 0 & \\
\hline 1 & 0 & 1 & 3 & \\
\hline$\geqslant 2$ & 9 & 10 & 12 & \\
\hline Diffuse & 1 & 6 & 1 & NS \\
\hline $\begin{array}{l}\text { Data are number of subjects or mec } \\
\text { " } \mathrm{p} \text { Value between the three age gro } \\
\mathrm{HDL} \text {, high density lipoprotein; NS, }\end{array}$ & & & & \\
\hline
\end{tabular}

to valve lesions were found in two valves of the young subjects, none of the valves of the middle aged subjects, and three valves of the elderly subjects. Cholesterol crystals in the right coronary cusp of the aortic valve were found in only one young subject, in seven middle aged, and nine elderly subjects. Microscopic calcification in the right coronary cusp was found in one young subject, 12 middle aged, and 14 elderly subjects. In both the middle aged and elderly groups, eight subjects had moderate or major valvar calcification. In the middle aged group microscopic calcification was detected at the base of the valve. Figure 3 shows some of the histological features of advanced aortic valve lesions in the oldest age group.

\section{DISCUSSION}

Our objective was to investigate the presence of atherosclerosis-like lesions in aortic valves of unselected Finnish

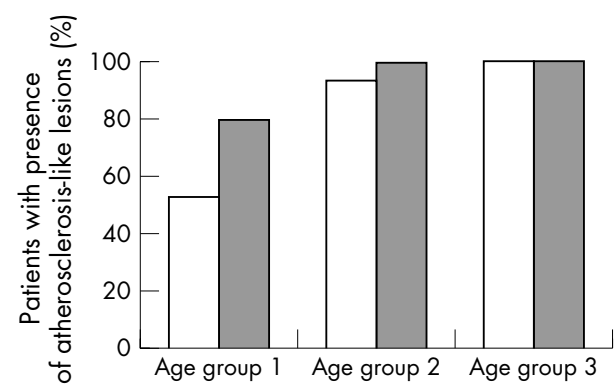

Figure 2 Presence of atherosclerosis-like lesions by age in the right coronary cusp of the aortic valve (open bars) and in any of the three aortic valve leaflets (grey bars). Age group 1: subjects aged 20-40 years; group 2: $41-60$ years; group 3: $\geqslant 61$ years. adults undergoing necropsy. None of the study subjects had aortic stenosis but atherosclerosis-like changes in aortic valves were present in 45 of 48 subjects aged $\geqslant 20$ years. The size of the atherosclerosis-like lesion appeared to be very age dependent but small lesions were found also in most young and all middle aged adults, which is a novel finding.

\section{Atherosclerosis-like lesions in non-stenosed aortic valves}

In the present study, atherosclerosis-like changes in aortic valves were present in 45 of 48 subjects aged $\geqslant 20$ years. These changes were characterised by subendothelial thickening on the aortic side of the valve leaflet above the elastic lamina, the presence of lipids and fine mineralisation in and adjacent to these lesions, and macrophages as well as occasional $\mathrm{T}$ cells as described by Otto and colleagues. ${ }^{2}$

In the present study, all elderly and middle aged subjects had atherosclerosis-like lesions in their aortic valves. Only one previous study investigated the presence of atherosclerosislike lesions in non-stenosed aortic valves. ${ }^{2}$ In the study by Otto and colleagues, ${ }^{2}$ most (14 of 15) macroscopically noncalcified aortic valves of elderly (mean age 62.0 years) American subjects undergoing necropsy had atherosclerosislike lesions, which is in accordance with the present study.

In our study, we observed valvar atherosclerosis-like lesions in most young subjects aged $20-40$ years (mean age 29.1 years). In contrast, in the study by Otto and colleagues, ${ }^{2}$ none of the six young (mean age 20.0 years) American necropsy subjects used as normal controls had atherosclerosislike lesions in their aortic valves. Compared with the American study, the present study examined a higher number of young subjects with a wider age distribution, which may explain the difference between the two studies. On the other hand, aortic stenosis is regarded as a form of atherosclerotic disease and atherosclerotic changes in the 
Table 3 Areas of the aortic valve cusps and atherosclerosis-like lesions in each cusp by age

\begin{tabular}{|c|c|c|c|c|}
\hline & \multicolumn{3}{|c|}{ Age group (years) } & \multirow[b]{2}{*}{ p Value* } \\
\hline & $\begin{array}{l}1(20-40) \\
(n=15)\end{array}$ & $\begin{array}{l}2(41-60) \\
(n=17)\end{array}$ & $\begin{array}{l}3(\geqslant 61) \\
(n=16)\end{array}$ & \\
\hline \multicolumn{5}{|l|}{ Right coronary cusp } \\
\hline Total area $\left(\mathrm{mm}^{2}\right)$ & $6.06(0.57)$ & $6.03(0.33)$ & 9.57 (1.37) & 0.072 \\
\hline Lesion area $\left(\mathrm{mm}^{2}\right)$ & $0.21(0.09)$ & $0.49(0.15)$ & $1.80(0.63)$ & $<0.001$ \\
\hline \multicolumn{5}{|l|}{ Left coronary cusp } \\
\hline Total area $\left(\mathrm{mm}^{2}\right)$ & $6.84(0.50)$ & $8.65(0.70)$ & $10.72(0.88)$ & 0.002 \\
\hline Lesion area $\left(\mathrm{mm}^{2}\right)$ & $0.20(0.06)$ & $0.70(0.13)$ & $1.33(0.35)$ & $<0.001$ \\
\hline \multicolumn{5}{|l|}{ Non-coronary cusp } \\
\hline Total area $\left(\mathrm{mm}^{2}\right)$ & $6.65(0.59)$ & $9.42(0.77)$ & $10.85(1.04)$ & 0.006 \\
\hline Lesion area $\left(\mathrm{mm}^{2}\right)$ & $0.05(0.03)$ & $0.83(0.17)$ & $2.28(0.71)$ & $<0.001$ \\
\hline
\end{tabular}

aortic valve may reflect the atherosclerotic process in coronary arteries. ${ }^{11}{ }^{12}$ Thus, the high prevalence of atherosclerosis-like lesions in the aortic valves of the young and middle aged subjects in the present study may reflect the high prevalence of coronary heart disease in the Finnish population. ${ }^{16}$ This view is supported by the coexistence of atherosclerosis-like lesions in aortic valves and macroscopically detected coronary disease in many subjects of the present study.

\section{Calcification, cholesterol crystals, and inflammatory cells}

Calcification is a hallmark of aortic stenosis and seems to be an active process regulated by osteopontin. ${ }^{17}$ In the current study, calcification of the aortic valve was a feature of a more advanced lesion, which was present in most middle aged and elderly subjects but absent from all but one subject of the youngest age group. Accordingly, in the study by Otto and colleagues, ${ }^{2}$ larger calcified valvar nodules were associated

\begin{tabular}{|c|c|c|c|c|}
\hline & \multicolumn{3}{|c|}{ Age group (years) } & \multirow[b]{2}{*}{ p Value ${ }^{*}$} \\
\hline & $\begin{array}{l}1(20-40) \\
(n=15)\end{array}$ & $\begin{array}{l}2(41-60) \\
(n=17)\end{array}$ & $\begin{array}{l}3(\geqslant 61) \\
(n=16)\end{array}$ & \\
\hline \multicolumn{5}{|l|}{ Location of aortic valve lesion } \\
\hline Base & 3 & 5 & 0 & \\
\hline Middle & 1 & 2 & 0 & \\
\hline Tip & 3 & 1 & 0 & \\
\hline Diffuse & 1 & 8 & 16 & $<0.001$ \\
\hline \multicolumn{5}{|l|}{ Internal elastic lamina } \\
\hline Normal & 7 & 1 & 0 & \\
\hline Dislocated & 5 & 8 & 16 & \\
\hline Disrupted & 1 & 1 & 1 & \\
\hline Duplicated & 0 & 0 & 1 & \\
\hline Multiple abnormalities & 2 & 7 & 8 & 0.004 \\
\hline \multicolumn{5}{|l|}{ Cellularity } \\
\hline Normal & 9 & 3 & 1 & \\
\hline Slightly increased & 5 & 12 & 10 & \\
\hline Moderately increased & 0 & 2 & 4 & \\
\hline Strongly increased & 1 & 0 & 1 & 0.002 \\
\hline \multicolumn{5}{|l|}{ Number of macrophages } \\
\hline Normal & 8 & 1 & 1 & \\
\hline Slightly increased & 1 & 3 & 1 & \\
\hline Moderately increased & 0 & 1 & 2 & \\
\hline Strongly increased & 1 & 1 & 1 & 0.028 \\
\hline \multicolumn{5}{|l|}{ Number of T lymphocytes } \\
\hline None & 8 & 5 & 1 & \\
\hline Slightly increased & 2 & 0 & 2 & \\
\hline Moderately to strongly increased & 0 & 0 & 1 & 0.051 \\
\hline \multicolumn{5}{|l|}{ Amount of cholesterol crystals } \\
\hline None & 14 & 10 & 7 & \\
\hline Slightly increased & 0 & 6 & 5 & \\
\hline Moderately increased & 1 & 1 & 2 & \\
\hline Strongly increased & 0 & 0 & 2 & 0.007 \\
\hline \multicolumn{5}{|l|}{ Amount of mineralisation } \\
\hline None & 14 & 5 & 2 & \\
\hline Slightly increased & 1 & 4 & 6 & \\
\hline Moderate to strongly increased & 0 & 8 & 8 & $<0.001$ \\
\hline \multicolumn{5}{|l|}{ Location of mineralisation } \\
\hline Base & 1 & 11 & 6 & \\
\hline Middle & 0 & 1 & 1 & \\
\hline Tip & 0 & 0 & 0 & \\
\hline Diffuse & 0 & 0 & 7 & 0.007 \\
\hline
\end{tabular}



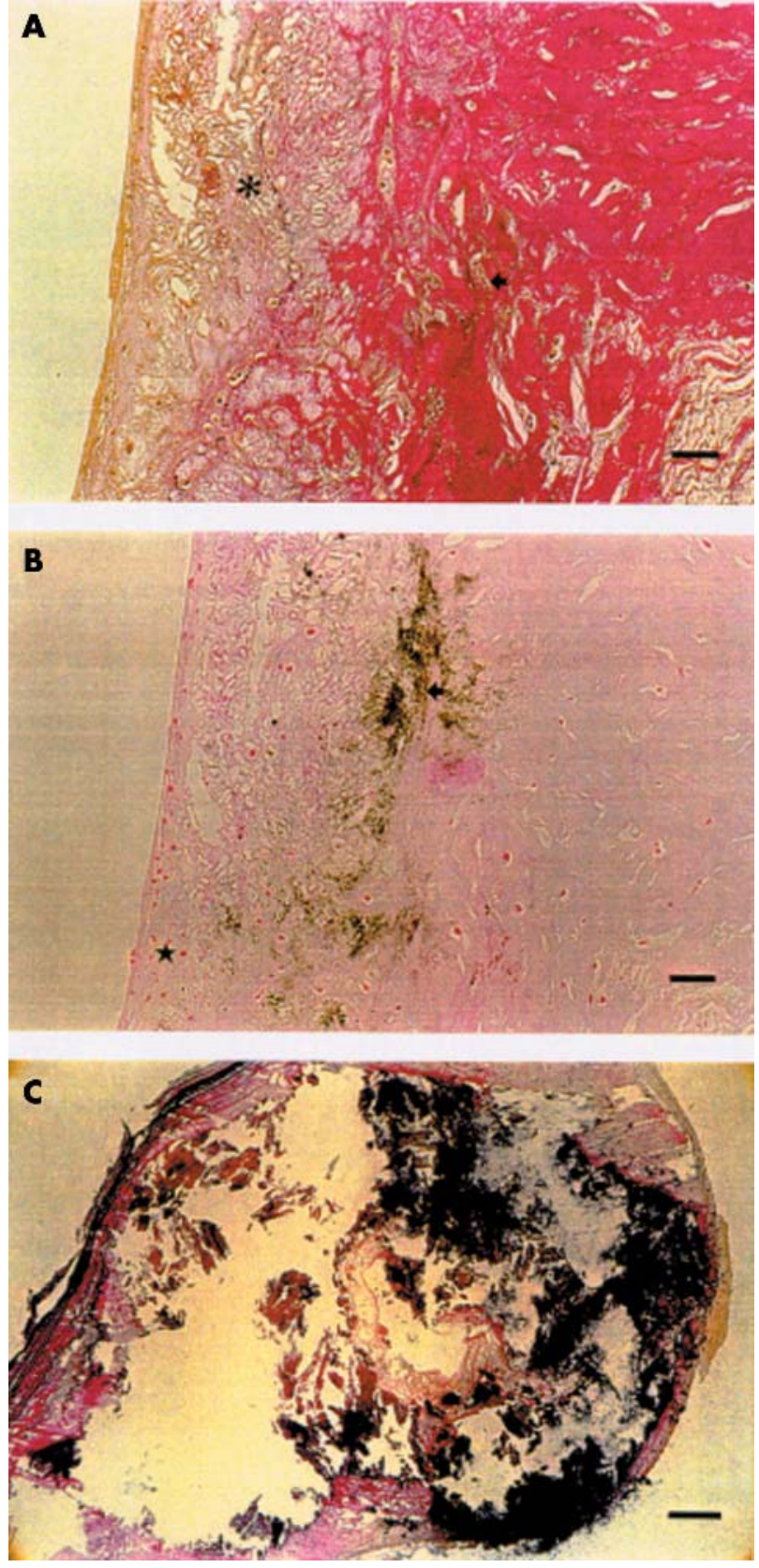

Figure 3 Photomicrographs of advanced lesions in the oldest age group. (A) Verhoeff-van Gieson stain shows cholesterol crystals (asterisk) and mineralisation (arrow). Bar $=60 \mu \mathrm{m}$. (B) Von Kossa stain shows slightly increased cellularity (star) as well as mineralisation (arrow) in the same specimen. Bar $=60 \mu \mathrm{m}$. (C) A large calcified lesion.

Bar $=100 \mu \mathrm{m}$. Verhoeff-van Gieson stain.

with a more severe macroscopic valvar disease. In coronary atherosclerotic lesions of young subjects, calcification is also rarely found. ${ }^{4}$ In the present study, the calcification process appeared to begin at the base, where the aortic valve attaches to the aortic root and where calcified lesions may restrict opening of the valve.

Extracellular cholesterol crystals were a feature of a more advanced lesion and were found mainly in middle aged and elderly subjects of the present study. Also in coronary atherosclerotic lesions of young subjects, extracellular cholesterol crystals are rarely found. ${ }^{4}$ In the present study, inflammatory cells were found in only a quarter to a half of the valves, mainly in or adjacent to more advanced lesions, implying that inflammatory cells are a part of an active valvar lesion. Accordingly, in the study by Otto and colleagues, ${ }^{2}$ macrophages were found in $65 \%$ of the aortic valves with mild macroscopic disease and $100 \%$ of those with clinical aortic stenosis and $\mathrm{T}$ lymphocytes were found in $54 \%$ of the lesions.

\section{Features of aortic valve lesions in young compared with older subjects}

Atherosclerosis-like lesions were found in aortic valves of most ( 12 of 15) young adults. The valvar lesions of the young were smaller and abnormalities of the internal elastic lamina were milder than those of middle aged and elderly subjects. Cholesterol crystals and mineralisation were rarely seen. Macrophages and $\mathrm{T}$ lymphocytes were seen in few valves of the young subjects.

When comparing the young, middle aged, and elderly groups, the size of the valvar lesions increased many-fold and lesions were more severe with increasing age, suggesting a progressive disease process often beginning in early adulthood.

\section{Limitations of the study}

Our study consisted of a moderate number of necropsy subjects in a population with a high prevalence of atherosclerosis. Moreover, most middle aged and elderly subjects had significant coronary disease and many of them died of myocardial infarction. Consequently, our results may not reflect the precise prevalence of aortic valve lesions in other western populations or even in the general Finnish population. In all young subjects, however, the cause of death was accident or suicide and not atherosclerotic vascular disease, suggesting that aortic valve lesions are, indeed, common in this age group in the Finnish population. Presumably, in populations with a lower prevalence of general atherosclerosis, atherosclerosis-like lesions in the aortic valve are also less common. Large scale studies, however, are needed to confirm the prevalence of atherosclerosis-like lesions in the aortic valve in different populations.

\section{Conclusions}

Atherosclerosis-like lesions in the aortic valve are prevalent in Finnish adults of all age groups, including young subjects aged 20-40 years. Atherosclerosis-like lesions in macroscopically non-calcified aortic valves have been interpreted as the early lesion of aortic stenosis. Consequently, our findings suggest that the disease process leading to aortic stenosis, like that of coronary atherosclerosis, is common, often beginning in early adulthood.

\section{ACKNOWLEDGEMENTS}

We gratefully acknowledge Anna-Liisa Gidlund and Tuija Nenonen for their skilful technical assistance.

\section{Authors' affiliations}

J Kuusisto, Department of Medicine, University of Kuopio and Kuopio University Hospital, Kuopio, Finland

K Räsänen, Department of Anaesthesiology, University of Helsinki, Helsinki, Finland

T Särkioja, Department of Forensic Medicine, University of Oulu, Oulu, Finland

E Alarakkola, Department of Pathology, University of Helsinki, Helsinki, Finland

V-M Kosma, Department of Pathology, University of Tampere and Tampere University Hospital, Tampere, Finland

\section{REFERENCES}

1 Stewart FB, Siscovick D, Lind BK, et al. Clinical factors associated with calcific aortic valve disease. J Am Coll Cardiol 1997;29:630-4. 
2 Otto CM, Kuusisto J, Reichenbach DD, et al. Characterization of the early lesion of degenerative valvular aortic stenosis: histological and immunohistochemical studies. Circulation 1994;90:844-53.

3 Olsson M, Dahlsgaard CJ, Haegerstrand A, et al. Accumulation of T lymphocytes and expression of interleukin-2 receptors in nonrheumatic stenotic aortic valves. J Am Coll Cardiol 1994;23:1162-70.

4 Badimon JJ, Fuster V, Chesebro JH, et al. Coronary atherosclerosis: a multifactorial disease. Circulation 1993;87(suppl II):113-16.

5 O'Brien KD, Reichenbach DD, Marcovina SM, et al. Apolipoproteins B, (a), and $E$ accumulate in the morphologically early lesion of degenerative valvular aortic stenosis. Arterioscler Thromb Vasc Biol 1996; 16:523-32.

6 Juvonen J, Laurila A, Juvonen T, et al. Detection of Chlamydia pneumoniae in human nonrheumatic stenotic aortic valves. J Am Coll Cardiol 1997;29:1054-9

7 Juvonen J, Juvonen T, Laurila A, et al. Can degenerative aortic valve stenosis be related to persistent Chlamydia pneumoniae infection? Ann Intern Med 1998;128:741-4.

8 O'Brien KD, Shavelle DM, Caulfield MT, et al. Association of angiotensinconverting enzyme with low-density lipoprotein in aortic valvular lesions and human plasma. Circulation 2002; 106:224-30

9 Agmon Y, Khanderia B, Meissner I, et al. Aortic valve sclerosis and aortic atherosclerosis: different manifestations of the same disease? J Am Coll Cardiol $2001 ; 38: 827-34$
10 Novaro GM, Sachar R, Pearce GL, et al. Association between apolipoprotein $E$ alleles and calcific valvular heart disease. Circulation 2003; 108:1804-8.

11 Otto CM, Lind KB, Kitzman DW, et al for the cardiovascular health study Association of aortic-valve sclerosis with cardiovascular mortality and morbidity in the elderly. N Engl J Med 1999;341:142-7.

12 Carabello BA. Aortic sclerosis: a window to the coronary arteries [editorial]? N Engl J Med 1999;341:193-4.

13 Wierzbicki A, Shetty C. Aortic stenosis: an atherosclerotic disease? J Heart Valve Dis 1999;4:416-23.

14 Otto CM, O'Brien KD. Why is there discordance between calcific aortic stenosis and coronary artery disease? [editorial] Heart $2001 ; 85: 601-2$.

15 Alpert JS. Aortic stenosis: a new face for an old disease. [editorial] Arch Intern Med 2003; 163:1769-70.

16 Tunstall-Pedoe $\mathbf{H}$, Kuulasmaa K, Mahonen $\mathrm{M}$, et al. Contribution of trends in survival and coronary-event rates to changes in coronary heart disease mortality: 10-year results from 37 WHO MONICA project populations. Monitoring trends and determinants in cardiovascular disease. Lancet 1999:353:1540-1.

17 O'Brien KD, Kuusisto J, Reichenbach DD, et al. Osteopontin is expressed in human aortic valvular lesions. Circulation 1995;92:2163-8.

\section{IMAGES IN CARDIOLOGY}

\section{Ventricular non-compaction cardiomyopathy: CMR and pathology findings}

A 39 year-old woman was diagnosed by non-invasive imaging techniques as having isolated ventricular noncompaction cardiomyopathy with severe left ventricular dysfunction. Cardiovascular magnetic resonance (CMR) study showed manifest apical trabeculation with deep intertrabecular recesses and thinning of the myocardial wall, characteristic of non-compaction cardiomyopathy (panel A). Contrast enhanced CMR images showed confluent areas of gadolinium enhancement in the interventricular septum, suggesting the presence of severe myocardial fibrosis in this territory (panel B). Six months later she underwent successful cardiac transplantation. Pathological findings identified abundant extracellular matrix within the myocardium and myocardial fibre disarray (panels $\mathrm{C}$ and $\mathrm{D}$ ).

To our knowledge, this is the first report of a case of non-compaction cardiomyopathy which showed a correlation between myocardial late enhancement by CRM and histopathologically proven myocardial fibrosis.

S Pujadas

R Bordes

A Bayes-Genis spujadas@hsp.santpau.es

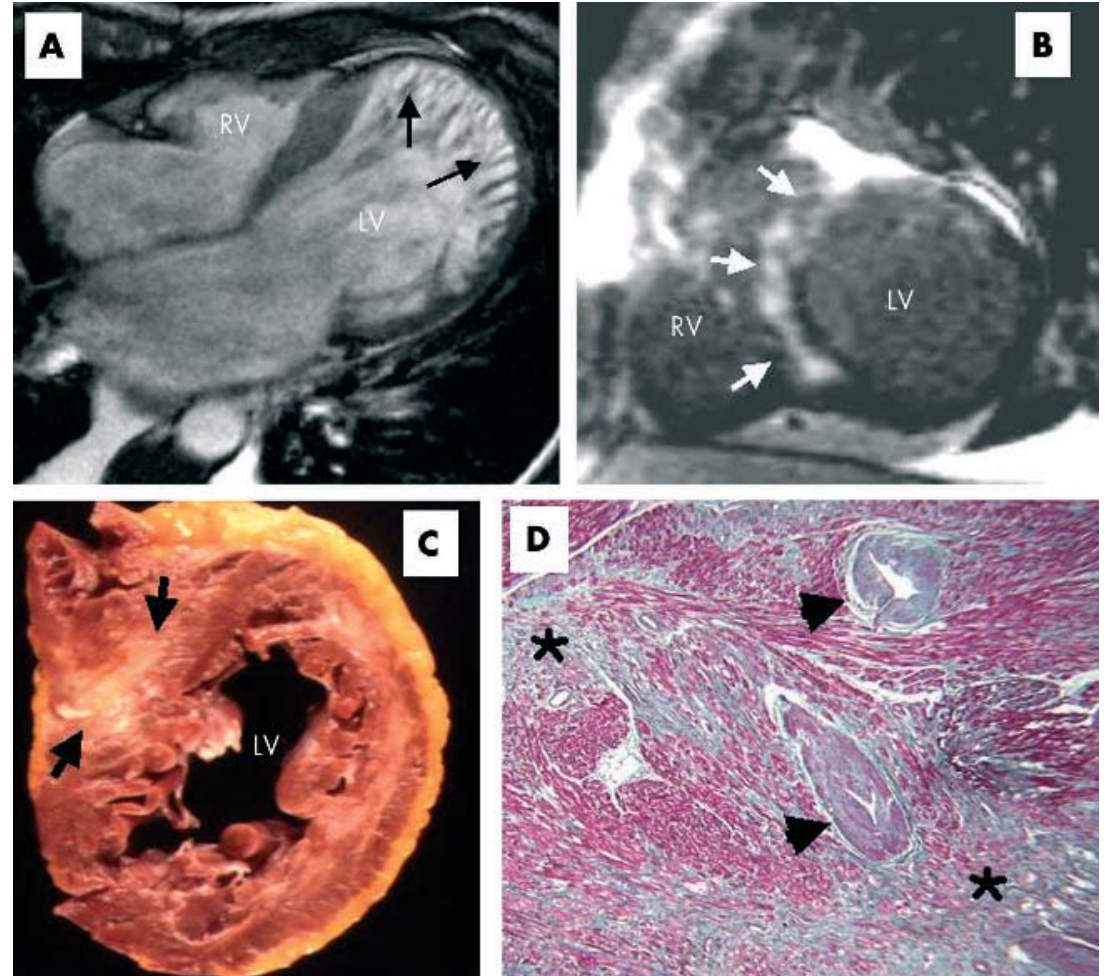

(A) Cardiovascular magnetic resonance (CMR) (balanced FFE sequence) showing apical trabeculation with deep intertrabecular recesses (arrows). (B) Contrast enhanced CMR showed confluent areas of gadolinium enhancement in interventricular septum (arrows). (C) Macroscopic examination of the heart revealed a yellowish area of interventricular septum suggestive of myocardial fibrosis, in agreement with gadolinium enhancement findings (arrows). (D) Microscopic examination (Masson's trichrome) showed the characteristic findings of non-compaction cardiomyopathy: abundant extracellular matrix (asterisk) intermingled with myocardial fibre disarray and severe hyperplasia of vascular media (arrowheads). LV, left ventricle; RV, right ventricle. 